OPEN ACCESS

Edited by:

Sabina Cevoli,

IRCCS Institute of Neurological

Sciences of Bologna (ISNB), Italy

Reviewed by:

Fabrizio Vernieri,

Campus Bio-Medico University, Italy

Lanfranco Pellesi,

Danish Headache Center, Denmark

*Correspondence: Javier Díaz de Terán javierddt@gmail.com

Specialty section: This article was submitted to Headache Medicine and Facial Pain,

a section of the journal

Frontiers in Neurology

Received: 22 June 2020 Accepted: 26 August 2020

Published: 15 October 2020

Citation:

Sastre Real M and Díaz de Terán J (2020) OnabotulinumtoxinA Is an

Effective Treatment for Chronic Migraine in Patients With Comorbid Fibromyalgia.

Front. Neurol. 11:575130. doi: 10.3389/fneur.2020.575130

\section{OnabotulinumtoxinA Is an Effective Treatment for Chronic Migraine in Patients With Comorbid Fibromyalgia}

\author{
María Sastre Real ${ }^{1,2}$ and Javier Díaz de Terán ${ }^{1,2,3 *}$ \\ ${ }^{1}$ Department of Neurology, La Paz University Hospital, Madrid, Spain, ${ }^{2}$ La Paz Institute for Health Research (IdiPAZ), Madrid, \\ Spain, ${ }^{3}$ CranioSPain Research Group, La Salle Higher Center for University Studies, Physiotherapy Department, \\ Autonomous University of Madrid, Madrid, Spain
}

Introduction: Fibromyalgia (FM) is a frequent comorbidity in patients with chronic migraine (CM). PREEMPT trials, which demonstrated the efficacy of OnabotulinumtoxinA (OnabotA) on CM, excluded patients with FM. Our aim was to evaluate the effectiveness of OnabotA in a series of patients with CM and FM.

Methods: We analyzed patients with a previous diagnosis of CM and FM who had received sessions of OnabotA quarterly between January 2014 and January 2020 in a specialized Headache Clinic. Primary endpoint was the reduction in moderate to severe headache days at 3, 6, 9, and 12 months.

Results: Data were collected from 31 patients with CM and FM that received OnabotA (100\% females). Mean age at first procedure was $50.2 \pm 11.3$ years. Depression (93.5\%), other central sensitization syndromes (irritable bowel syndrome, interstitial cystitis, multiple chemical sensitivity, endometriosis, and chronic fatigue syndrome) (48.4\%), and medication overuse headache (90.3\%) were frequent comorbidities. $48.4 \%$ of patients had failed $\geq 3$ preventives previously. The percentage of patients who achieved $\geq 30$ and $\geq 50 \%$ moderate-severe headache reduction on the third month was 65.4 and $48.2 \%$, respectively. Twenty-three patients completed four cycles of treatment, with 13.4 fewer headache days per month than at baseline $(p<0.001)$. By 1 year, $69.5 \%$ had $\geq 50 \%$ reduction of headache frequency and $39.1 \%$ had $a \geq 75 \%$ reduction. In 4 cases (21\%), OnabotA was interrupted due to a lack of response. Only mild adverse effects were recorded.

Conclusion: OnabotA is an effective treatment for CM in patients with FM.

Keywords: chronic migraine, fibromyalgia, onabotulinumtoxinA, central sensitization, comorbidities, quality of life

\section{INTRODUCTION}

Chronic migraine (CM) and fibromyalgia (FM) are prevalent and disabling pain disorders that frequently coexist (1). CM is defined as headache occurring on 15 or more days/month for more than 3 months, which, on at least 8 days/month, has the features of migraine headache (2). CM affects $2 \%$ of the general population and results in substantially greater disability than episodic migraine. Patients with CM are also more likely to have comorbid disorders such as depression, anxiety, and other chronic pain (3). 
FM is a chronic pain syndrome characterized by diffuse pain in addition to disturbed sleep, cognitive impairment, and/or pronounced fatigue $(4,5)$. Many studies have reported high rates of FM in patients with migraine, that range between 10 and $31 \%$ in patients with episodic migraine (6-12), and from 37 to $80 \%$ in patients with CM $(9,10,13,14)$. Migraineurs with comorbid FM report more depressive symptoms, higher headache intensity, and more disability (15).

Central sensitization has been purposed to be the common mechanism in both FM and migraine pathogenesis (6, 16-21). Cutaneous allodynia, low pain thresholds, and dysfunction of brainstem and cortical areas involved in the modulation and processing of pain have been found in patients with CM (2224). Taken together, this suggests that central pain processing dysfunction may be linked to both migraine chronicity and spreading of pain that results in development of FM. Other central sensitization syndromes are irritable bowel syndrome, interstitial cystitis, multiple chemical sensitivity, endometriosis, and chronic fatigue syndrome.

OnabotulinumtoxinA (OnabotA) is a treatment specifically approved for the prophylaxis of CM. Its efficacy has been demonstrated in two large Phase 3 trials (PREEMPT 1 and 2), together enrolling 1,354 individuals $(25,26)$. Subsequent analyses showed consistent results and a cumulative benefit over time $(27,28)$. Treatment of $\mathrm{CM}$ with OnabotA was associated with a sustained reduction in headache frequency, reduction in acute medications, and significant improvement in quality-of-life and disability measures. Moreover, symptoms of depression, anxiety, poor sleep and fatigue were all improved (27-34). Several studies demonstrated that $60-80 \%$ of patients reported a long-term reduction in headache days and/or migraine days of at least $50 \%$ from baseline (35-39).

Patients with FM were excluded from the PREEMPT trials $(25,26)$. Even though FM is a frequent comorbidity in patients with $\mathrm{CM}$ and contributes to disability, studies that analyze the response to preventive treatments in this subgroup of patients have been lacking (40). To the best of our knowledge, no studies designed to evaluate the response to OnabotA for CM in patients with FM have been published. The aim of the present study is to assess the effectiveness of OnabotA in this group of patients.

\section{MATERIALS AND METHODS}

This was a retrospective, observational study carried out in the city of Madrid, Spain, at a specialized Headache Clinic. We conducted a review of patient data accumulated in the normal conduct of standard medical practice. No prospective treatment assignments were made, and all assessments were routine standard of care. The study was reviewed and approved by the local Ethics Committee for Clinical Research of a public reference hospital (PI-3882). All patient data were treated with confidentiality, in accordance with the Declaration of Helsinki (41).

Subjects with FM were selected for recruitment from a database of patients that attended our Headache Clinic between June 2019 and January 2020. We reviewed the medical charts of those patients from January 2014 to January 2020. Subjects were included in this study if they met the following requirements: (1) had a diagnosis of $\mathrm{CM}$ according to the International Classification of Headache Disorders 3 (ICHD-3) criteria; (2) had received a diagnosis of FM from a rheumatologist following the 2010 criteria of the American College of Rheumatology; and (3) had received injections of OnabotA for the treatment of CM between January 2014 and January 2020.

Patients were excluded if they had a previous diagnosis of primary or secondary headache that could interfere with the effectivity measures, neuromuscular disease, or any contraindications for treatment with OnabotA.

Patient demographic data, headache history, and clinical features were obtained through a standardized oral questionnaire at baseline. Data regarding acute and prophylactic medications for headache or for other conditions were also documented.

OnabotA was initiated in patients who had either not responded to at least two oral preventive treatments or had contraindications or risk factors precluding the use of oral prophylactic medications. Subjects received intramuscular OnabotA injections following the PREEMPT paradigm (155-195 units in 31-39 sites) every 3 months ( \pm 2 weeks). The response to this treatment was evaluated quarterly. Prior preventative treatments were continued at the discretion of the treating neurologist. Success was defined as a $\geq 30 \%$ reduction in headache days per month or a clinically significant improvement of headache disability reported by the patient. OnabotA therapy was discontinued if treatment success was not achieved over the first three treatment cycles.

As per usual clinical practice, patients maintained a paper or electronic diary during the OnabotA treatment period to register headache days and acute medication intake. The first year of treatment (four cycles) was considered to analyze the effectiveness and tolerability of OnabotA (42). The primary endpoint was reduction in moderate to severe headache frequency at 3, 6, 9, and 12 months in accord with the Guidelines of the International Headache Society for controlled trials of preventive treatment of $\mathrm{CM}$ in adults. A moderate/severe headache day was defined as a day with moderate or severe pain lasting at least $4 \mathrm{~h}$ or a day with a headache that was successfully treated by an acute headache medication (43). We considered moderate to severe headache as the primary endpoint because it is difficult for the patients to register all headache features for each attack and these definitions allow the use of a relatively simple headache diary.

We used ANOVA (significance level $\leq 0.05$ ) to test for statistical significance of reported headache days per month between baseline and at 3, 6, 9, and 12 months. Statistical analyses were performed with IBM SPSS Statistics 25.0 (IBM, Armonk, NY).

\section{RESULTS}

We included 31 patients diagnosed with CM and concomitant FM that met eligibility criteria. Demographic and baseline patient characteristics are provided in Table 1. At least three 
TABLE 1 | Demographic and baseline clinical characteristics.

\begin{tabular}{lc}
\hline Variables & $N=31$ \\
Age (years) (mean, SD) & $50.2,11.3$ \\
Gender (, \%) & \\
$\quad$ Female & $31(100)$ \\
$\quad$ Male & $0(0)$ \\
Comorbidities ( $n, \%)$ & \\
$\quad$ Depression & $29(93.5)$ \\
$\quad$ Medication overuse headache & $28(90.3)$ \\
$\quad$ Other central sensitization syndromes & $15(48.4)$ \\
$\quad$ Other chronic pain syndrome & $27(87.1)$ \\
$\quad$ Autoimmune disease & $12(38.7)$ \\
Migraine duration (years) (mean, SD) & $24.5,15.7$ \\
Moderate/severe headache days per & $24.9,5.3$ \\
month (mean, SD) & \\
Prior failed preventive treatments $(n, \%)$ & \\
$\quad \geq 2$ & $27(87.1)$ \\
$\geq 3$ & $15(48.4)$ \\
$\quad \geq 4$ & $10(32.3)$ \\
Concomitant preventive treatment at first & $23(74.2)$ \\
injection $(n, \%)$ & \\
\hline
\end{tabular}

$S D=$ standard deviation

*Irritable bowel syndrome, interstitial cystitis, multiple chemical sensitivity, endometriosis, and chronic fatigue syndrome.

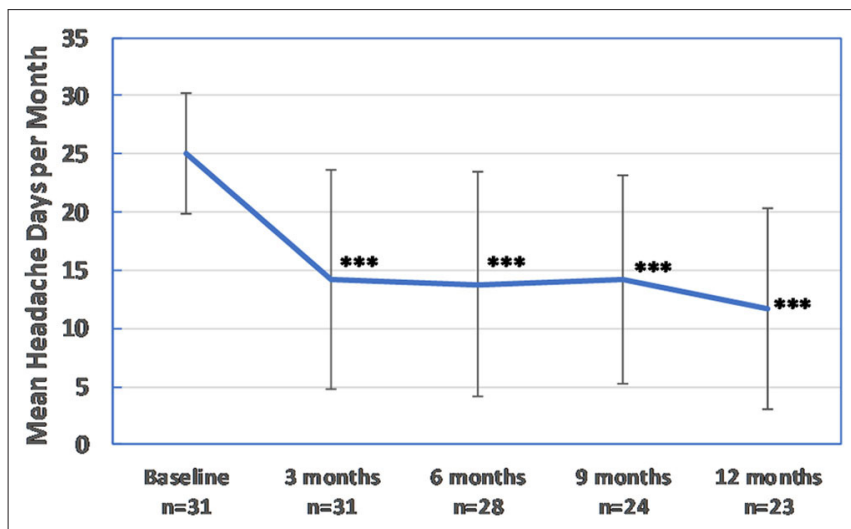

FIGURE 1 | Effectiveness of OnabotA: moderate to severe headache days per month. Error bars are \pm 1 standard deviation. ${ }^{\star \star *} p<0.001$ vs. baseline.

prior preventive treatments had failed in about half of the patients $(48.4 \%)$.

Among the 31 patients included, 23 (74.2\%) were receiving a concurrent oral preventive migraine therapy when OnabotA was initiated. Sixteen patients $(51.6 \%)$ were on antidepressants. Twenty-eight patients (90.3\%) fulfilled medication overuse headache $(\mathrm{MOH})$ criteria according to ICHD-3, including 21 (67.7\%) patients overusing opioids. Interestingly, only nine patients $(29 \%)$ overused analgesics solely to alleviate headache and only five patients (16.1\%) were triptan abusers. Most analgesic abusers (67.9\%) and opioids abusers (80.9\%) were consuming acute medications mainly to mitigate extracranial pain due to FM or pain conditions other than migraine.
A $\geq 30 \%$ reduction in headache days per month was achieved by $65.4 \%$ of patients at 3 months; $48.2 \%$ of patients achieved a $\geq 50 \%$ reduction, and $37.9 \%$ of patients achieved a $\geq 75 \%$ reduction. After one cycle of treatment, mean moderate to severe headache days were significantly reduced from $24.9 \pm 5.2$ to 14.2 $\pm 9.4(p<0.001)$. A total of 23 patients received at least four treatment cycles. After four cycles, $69.5 \%$ of patients experienced a reduction of at least $50 \%$ in moderate to severe headache days per month, and $39.1 \%$ reported a reduction of $\geq 75 \%$. Moderate to severe headache days per month were reduced from $25.1 \pm 5.2$ to $11.7 \pm 8.6(p<0.001)$. All patients with $\geq 50 \%$ response after one cycle continued being responders after 1 year of treatment. Treatment outcomes during 1 year of treatment are summarized in Figures 1, 2. OnabotA was discontinued in four patients (12.9\%) due to a lack of response. Four patients began treatment after January 2019 and were continuing treatment with $<1$ year of follow-up at the time of data analysis.

None of the patients discontinued their oral migraine prophylactic treatments. Of the 28 patients that fulfilled criteria for $\mathrm{MOH}$ at baseline, the condition was solved for 18 (64.3\%), reducing the prevalence from 90.3 to $32.3 \%$. Nevertheless, 24 patients continued to consume excessive medication ( $\geq 10$ days of triptans, $\geq 15$ days of NSAIDs, or $\geq 10$ days of opioids per month) for other pain conditions.

There were few reported adverse events for OnabotA and none were considered serious. Reported adverse events were ptosis in one patient (3.2\%) and mild vagal reaction in one patient (3.2\%).

\section{DISCUSSION}

$\mathrm{CM}$ is a prevalent and disabling neurologic disorder that is often associated with comorbid conditions that can influence both its prognosis and its impact on quality of life $(1,3,23)$.

Several studies have reported a high prevalence (up to $80 \%$ ) of FM in patients with $\mathrm{CM}(9,10,13,14)$, and there is a large body of evidence that central sensitization comprises the common pathophysiologic basis (1). FM and migraine when present together contribute to increased disability. Furthermore, the presence of FM often makes the management of $\mathrm{CM}$ less straightforward owing to the presence of concomitant treatments, widespread pain with the increased risk of analgesic abuse, and greater prevalence of psychiatric comorbidity.

Patients with both $\mathrm{CM}$ and FM require a tailored and multidisciplinary treatment approach. PREEMPT clinical trials and subsequent real-life studies have demonstrated the efficacy, safety, and tolerability of OnabotA as a prophylactic treatment for $\mathrm{CM}$ in adults $(25,27,30,35-37)$. However, patients with FM were excluded from the PREEMPT trials. Given the high prevalence of FM in CM patients, the lack of studies that evaluate responsiveness to $\mathrm{CM}$ treatments, and in particular to OnabotA, in this group of patients is surprising (40). Two Spanish studies that evaluated the effectiveness of OnabotA for CM included FM among other variables in their analysis and reported that FM did not significantly influence the rate of response to OnabotA (36, 37). However, the included FM patients comprised a relatively small subset of the study populations, and detailed assessment of 

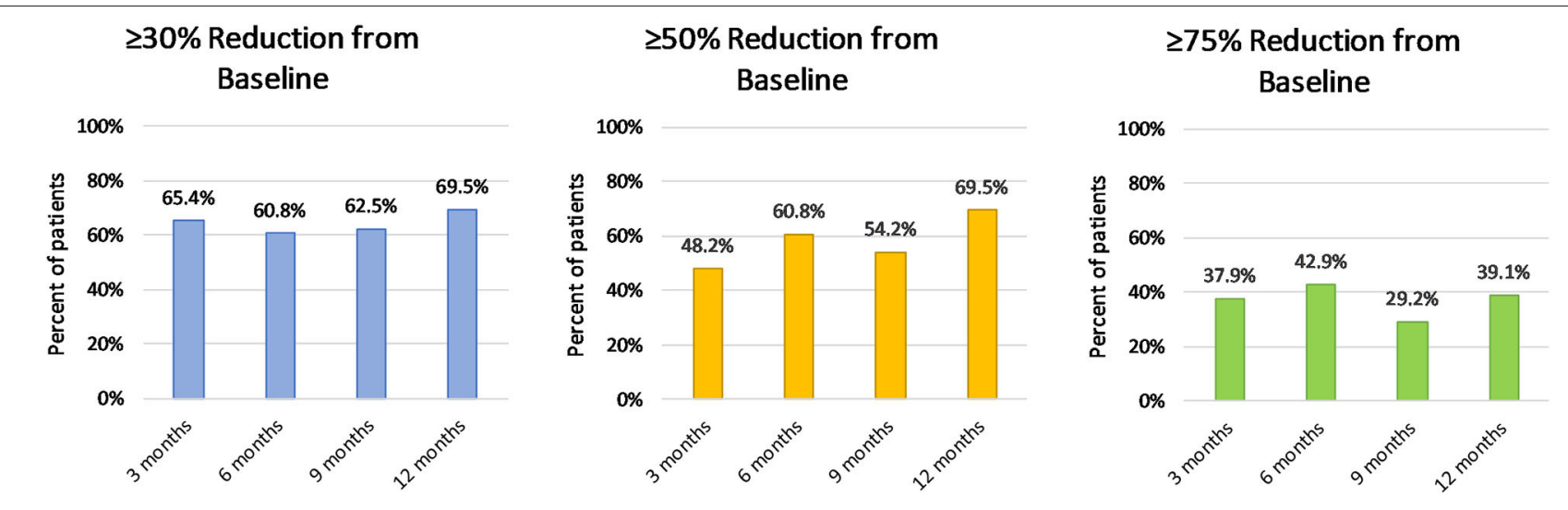

FIGURE 2 | Effectiveness of OnabotA: proportion of patients with $\geq 30, \geq 50$, and $\geq 75 \%$ reduction of moderate to severe headache days per month.

response was not reported for these patients with FM. To the best of our knowledge, this is the first study that specifically assesses the effectiveness of OnabotA for CM in a cohort of patients with FM.

Our results show that OnabotA is effective in patients with CM and FM. After 1 year of treatment, $69.5 \%$ of patients reduced their moderate to severe headache frequency by at least $50 \%$ and a mean headache days reduction of $13.4 \pm$ $10.0(p<0.001)$ was observed. This high response rate was in spite of the presence of several negative predictive factors such as long duration of CM, multiple prior preventive treatment failures, and several comorbidities. Importantly, 74.2\% of patients were treated for at least 1 year, minimizing the potential confounding influence of natural fluctuations in the disease course itself (42). The 1 year span of treatment highlights the long-term safety and tolerability of OnabotA, even in the presence of comorbidities. Our results are consistent with those of other real-world published studies on CM in terms of main efficacy measures $(33,35-37)$. However, other studies have reported high rates of concomitant prophylactic treatment discontinuation and reduction of acute medication intake with OnabotA (33), which was not observed in our study. It is worth emphasizing that most concomitant prophylactic medications used in our sample had a dual indication: both for migraine and depression or for migraine and concomitant extracephalic chronic pain conditions. Therefore, it is not surprising that patients continued to need those treatments, regardless of their migraine improvement. On the other hand, the vast majority of patients took acute medications (opioids in particular) to relieve other pain conditions (FM and other chronic pain syndromes). OnabotA significantly reduced headache frequency even though most of these patients continued to use excessive medication. Indeed, $\mathrm{MOH}$ reduced from 90.3 to $32.3 \%$. This finding, consistent with previous studies, confirms that OnabotA is effective in patients with $\mathrm{MOH}$ who do not receive withdrawal interventions (44-46). Thus, in patients with FM, even when reduction of acute medication use is not the short-term objective, headache frequency can be reduced without acute medication withdrawal. This finding reinforces the idea that the presence of FM, even with the abuser condition, should not preclude use of OnabotA.

The limitations of the present study include the retrospective, single-center design with a relatively small sample size, and the lack of a control group. Nevertheless, the efficacy results are consistent with those of large prospective observational studies. While the relatively "open" inclusion criteria could introduce variability, it was, in our view, a key strength. While randomized controlled trials have inarguable intrinsic validity, "real-world" data such as the cohort described herein have extrinsic validity.

The treatment of migraine should not be so narrow that comorbid conditions impinging on quality of life are ignored. FM evaluation and treatment should be considered in the daily practice of patients with migraine (47). This study showed OnabotA to be a safe and effective treatment for CM in patients with FM. Additional studies confirming these results are warranted.

\section{DATA AVAILABILITY STATEMENT}

The raw data supporting the conclusions of this article will be made available by the authors, without undue reservation.

\section{ETHICS STATEMENT}

The studies involving human participants were reviewed and approved by Comité de Ética de la Investigación con medicamentos del Hospital Universitario La Paz. Written informed consent for participation was not required for this study in accordance with the national legislation and the institutional requirements.

\section{AUTHOR CONTRIBUTIONS}

MS created the original manuscript draft and performed the data analysis. JD revised the original draft manuscript. MS and JD 
contributed equally to the conceptualization and design of the study. All authors contributed to the article and approved the submitted version.

\section{FUNDING}

Publication costs and financial support for medical writing were provided by Allergan UK (now Abbie) (project

\section{REFERENCES}

1. Penn IW, Chuang E, Chuang TY, Lin CL, Kao CH. Bidirectional association between migraine and fibromyalgia: retrospective cohort analyses of two populations. BMJ Open. (2019) 9:e026581. doi: 10.1136/bmjopen-2018-026581

2. Headache Classification Committee of the International Headache Society (IHS). The international classification of headache disorders, 3rd edition. Cephalalgia. (2018) 38:1-211. doi: 10.1177/0333102417738202

3. Schwedt TJ. Chronic migraine. BMJ. 348:g1416. doi: 10.1136/bmj.g1416

4. Wolfe F, Smythe HA, Yunus MB, Bennett RM, Bombardier C, Goldenberg DL, et al. The American College of Rheumatology 1990 criteria for the classification of fibromyalgia. Report of the Multicenter Criteria Committee. Arthritis Rheum. (1990) 33:160-72. doi: 10.1007/978-3-642-86812-2_2

5. Wolfe F, Clauw DJ, Fitzcharles MA, Goldenberg DL, Katz RS, Mease P, et al. The American College of Rheumatology preliminary diagnostic criteria for fibromyalgia and measurement of symptom severity. Arthritis Care Res. (2010) 62:600-10. doi: 10.1002/acr.20140

6. de Tommaso M. Prevalence, clinical features and potential therapies for fibromyalgia in primary headaches. Expert Rev Neurother. (2012) 12:28796. doi: 10.1586/ern.11.190

7. Marcus DA, Bhowmick A. Fibromyalgia comorbidity in a community sample of adults with migraine. Clin Rheumatol. (2013) 32:1553-6. doi: 10.1007/s10067-013-2310-7

8. Küçükşen S, Genç E, Yilmaz H, Salli A, Gezer IA, Karahan AY, et al. The prevalence of fibromyalgia and its relation with headache characteristics in episodic migraine. Clin Rheumatol. (2013) 32:98390. doi: 10.1007/s10067-013-2218-2

9. Evans RW, De Tommaso M. Migraine and fibromyalgia. Headache. (2011) 51:295-9. doi: 10.1111/j.1526-4610.2010.01835.x

10. Onder H, Hamamci M, Alpua M, Ulusoy EK. Comorbid fibromyalgia in migraine patients: clinical significance and impact on daily life. Neurol Res. (2019) 41:909-15. doi: 10.1080/01616412.2019.1630164

11. Tietjen GE, Herial NA, Hardgrove J, Utley C, White L. Migraine comorbidity constellations. Headache. (2007) 47:85765. doi: 10.1111/j.1526-4610.2007.00814.x

12. Ifergane G, Buskila D, Simiseshvely N, Zeev K, Cohen H. Prevalence of fibromyalgia syndrome in migraine patients. Cephalalgia. (2006) 26:4516. doi: 10.1111/j.1468-2982.2005.01060.x

13. Cho SJ, Sohn JH, Bae JS, Chu MK. Fibromyalgia among patients with chronic migraine and chronic tension-type headache: a multicenter prospective cross-sectional study. Headache. (2017) 57:1583-92. doi: 10.1111/head. 13191

14. De Tommaso M, Sardaro M, Serpino C, Costantini F, Vecchio E, Pia Prudenzano $M$, et al. Fibromyalgia comorbidity in primary headaches. Cephalalgia. (2009) 29:453-64. doi: 10.1111/j.1468-2982.2008.01754.x

15. Whealy M, Nanda S, Vincent A, Mandrekar J, Cutrer FM. Fibromyalgia in migraine: a retrospective cohort study. J Headache Pain. (2018) 19:61. doi: 10.1186/s10194-018-0892-9

16. Marcus DA, Bernstein C, Rudy TE. Fibromyalgia and headache: an epidemiological study supporting migraine as part of the fibromyalgia syndrome. Clin Rheumatol. (2005) 24:595601. doi: 10.1007/s10067-005-1121-x nr. PG-2020-10902). The funder was not involved in the study design, collection, analysis, interpretation of data, the writing of this article or the decision to submit it for publication.

\section{ACKNOWLEDGMENTS}

The authors acknowledged the editorial assistance of Jaime E. Dickerson, PhD (Coral Snake Consulting).

17. Tietjen GE, Brandes JL, Peterlin BL, Eloff A, Dafer RM, Stein MR, et al. Allodynia in migraine: association with comorbid pain conditions. Headache. (2009) 49:1333-44. doi: 10.1111/j.1526-4610.2009.01521.x

18. Staud R, Rodriguez ME. Mechanisms of disease: pain in fibromyalgia syndrome. Nat Clin Pract Rheumatol. (2006) 2:90-8. doi: 10.1038/ncprheum0091

19. de Tommaso M. Migraine and fibromyalgia. J Headache Pain. (2015) 16:A45. doi: 10.1186/1129-2377-16-S1-A45

20. de Tommaso M, Sciruicchio V, Delussi M, Vecchio E, Goffredo M, Simeone $\mathrm{M}$, et al. Symptoms of central sensitization and comorbidity for juvenile fibromyalgia in childhood migraine: an observational study in a tertiary headache center. J Headache Pain. (2017) 18:59. doi: 10.1186/s10194-017-0764-8

21. Grayston R, Czanner G, Elhadd K, Goebel A, Frank B, Üçeyler N, et al. A systematic review and meta-analysis of the prevalence of small fiber pathology in fibromyalgia: implications for a new paradigm in fibromyalgia etiopathogenesis. Semin Arthritis Rheum. (2019) 48:93340. doi: 10.1016/j.semarthrit.2018.08.003

22. Su M, Yu S. Chronic migraine: a process of dysmodulation and sensitization. Mol Pain. (2018) 14:1744806918767697. doi: 10.1177/1744806918767697

23. Aurora SK. Spectrum of illness: understanding biological patterns and relationships in chronic migraine. Neurology. (2009) 72:8-13. doi: 10.1212/WNL.0b013e31819749fd

24. Burstein R, Yarnitsky D, Goor-Aryeh I, Ransil BJ, Bajwa ZH. An association between migraine and cutaneous allodynia. Ann Neurol. (2000) 47:61424. doi: 10.1002/1531-8249(200005)47:5<614::AID-ANA9>3.0.CO;2-N

25. Diener HC, Dodick DW, Aurora SK, Turkel CC, DeGryse RE, Lipton RB, et al. OnabotulinumtoxinA for treatment of chronic migraine: results from the double-blind, randomized, placebo-controlled phase of the PREEMPT 2 trial. Cephalalgia. (2010) 30:804-14. doi: 10.1177/0333102410364677

26. Aurora SK, Dodick DW, Turkel CC, DeGryse RE, Silberstein SD, Lipton RB, et al. OnabotulinumtoxinA for treatment of chronic migraine: results from the double-blind, randomized, placebo-controlled phase of the PREEMPT 1 trial. Cephalalgia. (2010) 30:793-803. doi: 10.1177/0333102410364676

27. Aurora SK, Dodick DW, Diener HC, DeGryse RE, Turkel CC, Lipton RB, et al. OnabotulinumtoxinA for chronic migraine: efficacy, safety, and tolerability in patients who received all five treatment cycles in the PREEMPT clinical program. Acta Neurol Scand. (2014) 129:61-70. doi: 10.1111/ane.12171

28. Aurora SK, Winner P, Freeman MC, Spierings EL, Heiring JO, DeGryse RE, et al. OnabotulinumtoxinA for treatment of chronic migraine: pooled analyses of the 56-week PREEMPT clinical program. Headache. (2011) 51:135873. doi: 10.1111/j.1526-4610.2011.01990.x

29. Lipton RB, Varon SF, Grosberg B, McAllister PJ, Freitag F, Aurora SK, et al. OnabotulinumtoxinA improves quality of life and reduces impact of chronic migraine. Neurology. (2011) 77:1465-72. doi: 10.1212/WNL.0b013e318232ab65

30. Ahmed F, Gaul C, Garciá-Moncó JC, Sommer K, Martelletti P, REPOSE Principal Investigators. An open-label prospective study of the real-life use of onabotulinumtoxinA for the treatment of chronic migraine: the REPOSE study. J Headache Pain. (2019) 20:26. doi: 10.1186/s10194-019-0976-1

31. Khalil M, Zafar HW, Quarshie V, Ahmed F. Prospective analysis of the use of onabotulinumtoxinA (BOTOX) in the treatment of chronic migraine; real-life data in (2014) 254 patients from Hull, UK. J Headache Pain. 15:54. doi: 10.1186/1129-2377-15-54 
32. Negro A, D’Alonzo L, Lala N, Martelletti P. P070. A 2-year prospective evaluation study on onabotulinumtoxinA $155 \mathrm{U}$ in chronic migraine. $J$ Headache Pain. (2015) 16:A137. doi: 10.1186/1129-2377-16-S1-A137

33. Aicua-Rapun I, Martínez-Velasco E, Rojo A, Hernando A, Ruiz M, Carreres A, et al. Real-life data in 115 chronic migraine patients treated with onabotulinumtoxin A during more than one year. J Headache Pain. (2016) 17:112. doi: 10.1186/s10194-016-0702-1

34. Blumenfeld AM, Tepper SJ, Robbins LD, Manack Adams A, Buse DC, Orejudos A, et al. Effects of onabotulinumtoxinA treatment for chronic migraine on common comorbidities including depression and anxiety. J Neurol Neurosurg Psychiatry. (2019) 90:353-60. doi: 10.1136/jnnp-2018-319290

35. Blumenfeld AM, Stark RJ, Freeman MC, Orejudos A, Manack Adams A. Long-term study of the efficacy and safety of onabotulinumtoxinA for the prevention of chronic migraine: COMPEL study. J Headache Pain. (2018) 19:13. doi: 10.1186/s10194-018-0840-8

36. Domínguez C, Pozo-Rosich $\mathrm{P}$, Torres-Ferrús $\mathrm{M}$, Hernández-Beltrán $\mathrm{N}$, Jurado-Cobo C, González-Oria C, et al. OnabotulinumtoxinA in chronic migraine: predictors of response. A prospective multicentre descriptive study. Eur J. Neurol. (2018) 25:411-6. doi: 10.1111/ene.13523

37. Cernuda-Morollón E, Ramón C, Larrosa D, Alvarez R, Riesco N, Pascual J. Long-term experience with onabotulinumtoxinA in the treatment of chronic migraine: what happens after one year? Cephalalgia. (2015) 35:8648. doi: 10.1177/0333102414561873

38. Pedraza MI, de la Cruz C, Ruiz M, López-Mesonero L, Martínez E, de Lera $\mathrm{M}$, et al. OnabotulinumtoxinA treatment for chronic migraine: experience in 52 patients treated with the PREEMPT paradigm. Springerplus. (2015) 4:176. doi: 10.1186/s40064-015-0957-z

39. Kollewe K, Escher CM, Wulff DU, Fathi D, Paracka L, Mohammadi B, et al. Long-term treatment of chronic migraine with onabotulinumtoxinA: efficacy, quality of life and tolerability in a real-life setting. J Neural Transm. (2016) 123:533-40. doi: 10.1007/s00702-016-1539-0

40. Yilmaz V, Aras B, Erturk FA, Cakci FA, Umay E. Migraine in patients with fibromyalgia and outcomes of greater occipital nerve blockage. Clin Neurol Neurosurg. (2019) 181:54-7. doi: 10.1016/j.clineuro.2019.04.004

41. World Medical Association. World Medical Association Declaration of Helsinki: ethical principles for medical research involving human subjects. JAMA. (2013) 31:2191-4. doi: 10.1001/jama.2013.281053
42. Vernieri F, Paolucci M, Altamura C, Pasqualetti, P, Mastrangelo V, Pierangeli G, et al. Onabotulinumtoxin-A in chronic migraine: should timing and definition of non-responder status be revised? suggestions from a real-life italian multicenter experience. Headache. (2019) 59:13009. doi: 10.1111/head.13617

43. Tassorelli C, Diener HC, Dodick DW, Silberstein SD, Lipton RB, Ashina M, et al. Guidelines of the International Headache Society for controlled trials of preventive treatment of chronic migraine in adults. Cephalalgia. (2018) 38:815-32. doi: 10.1177/0333102418758283

44. Guerzoni S, Pellesi L, Baraldi C, Cainazzo MM, Negro A, Martelletti $\mathrm{P}$, et al. Long-term treatment benefits and prolonged efficacy of onabotulinumtoxinA in patients affected by chronic migraine and medication overuse headache over 3 years of therapy. Front Neurol. (2017) 8:586. doi: 10.3389/fneur.2017.00586

45. Caronna E, Gallardo VJ, Hernández-Beltrán N, Torres-Ferrus M, PozoRosich P. OnabotulinumtoxinA: an effective tool in the therapeutic arsenal for chronic migraine with medication overuse. Front Neurol. (2018) 9:808. doi: 10.3389/fneur.2018.00808

46. Butera C, Colombo B, Bianchi F, Cursi M, Messina R, Amadio S, et al. Refractory chronic migraine: is drug withdrawal necessary before starting a therapy with onabotulinum toxin type A? Neurol Sci. (2016) 37:17016. doi: 10.1007/s10072-016-2662-2

47. Beyazal MS, TüfekçI A, Kirbaș S, Topaloglu MS. The impact of fibromyalgia on disability, anxiety, depression, sleep disturbance, and quality of life in patients with migraine. Noro Psikiyatr Ars. (2018) 55:1405. doi: 10.5152/npa.2016.12691

Conflict of Interest: The authors declare that the research was conducted in the absence of any commercial or financial relationships that could be construed as a potential conflict of interest.

Copyright (c) 2020 Sastre Real and Díaz de Terán. This is an open-access article distributed under the terms of the Creative Commons Attribution License (CC BY). The use, distribution or reproduction in other forums is permitted, provided the original author(s) and the copyright owner(s) are credited and that the original publication in this journal is cited, in accordance with accepted academic practice. No use, distribution or reproduction is permitted which does not comply with these terms. 